\title{
Pharmacy Compounding Primer for Physicians Prescriber Beware
}

\author{
Sarah Sellers ${ }^{1}$ and Wulf H. Utian ${ }^{2}$ \\ 1 q-Vigilance LLC, North Barrington, IL, USA \\ 2 Case Western Reserve University, Cleveland, $\mathrm{OH}$, USA
}

\begin{abstract}
Since the development of federal standards for drug approval, the practice of medicine has historically involved the compounding of medications based on a physician's determination that a US FDA-approved product either did not exist, or could not be used for medical reasons. Today, prescriptions for non-FDA-approved compounded drugs may be driven by fanciful and largely unregulated pharmacy advertisements to physicians and patients and/or payer reimbursement policies, thus placing prescribers in the backseat for clinical decision making. This article outlines essential differences between FDA-approved drugs and compounded drugs and reasserts the primary medical role of physicians for determining what medical circumstances may necessitate treatment with non-FDA-approved products. In addition, liability concerns when prescribing non-FDA-approved drugs are discussed. While representing a US perspective, underlying principles apply globally in the setting of magistral and extemporaneous formulations produced outside national regulatory frameworks.
\end{abstract}

\section{Introduction}

Since the development of federal standards for drug approval, the professions of pharmacy and medicine have their earliest roots in drug compounding. In centuries past, doctors and pharmacists created individual therapies according to patient needs and the medical and scientific principles of the time. With the development of commercial manufacturing, pharmacies gradually transitioned into dispensaries of standardized drug products manufactured by the pharmaceutical industry and subject to federal oversight and regulation. While US FDA-approved drug products currently meet the therapeutic needs of most patients, there are certain circumstances in which compounded drugs play an important role in medical care. While the scope of the paper is focused primarily on the US experience, principles apply equally to magistral or extemporaneous formulations that are produced outside national regulatory frameworks around the globe and for which differentiation and discrimination of this unique benefit-risk setting is critical for therapeutic decision making.

\section{Drugs Approved and Regulated by the US FDA}

FDA-approved drugs include both branded and generic products. Branded drugs are rigorously reviewed by the FDA for quality, safety 
and efficacy under a New Drug Application (NDA). Approval of an NDA requires substantial evidence of effectiveness, defined under the Federal Food, Drug and Cosmetic Act (FFDCA) as "evidence consisting of adequate and well-controlled investigations by experts qualified by scientific training and experience to evaluate the effectiveness of the drug involved, on the basis of which it could fairly and responsibly be concluded by such experts that the drug will have the effect it purports or is represented to have under the conditions of use prescribed, recommended, or suggested in the proposed labeling." "[1] In general, drugs approved under an NDA have demonstrated a positive benefit-risk balance for their intended use on a population level. Generic drugs are reviewed and approved for quality and bioequivalency to an FDA-approved reference drug under an Abbreviated NDA (ANDA). Both brand and generic drugs are required by law to be produced under federal Good Manufacturing Practice (GMP) regulations, a detailed and complex set of working standards established through federal regulation to ensure products meet specific requirements for identity, quality, potency and purity. Pharmaceutical manufacturers are periodically inspected by the FDA for adherence to GMP regulations and to ensure that GMP-driven quality standards established for drugs manufactured for scientific evaluation in clinical trial populations ${ }^{[2]}$ are met or exceeded for drugs manufactured for commercial distribution. ${ }^{[3]}$

\section{Compounded Drugs and Traditional Pharmacy Compounding}

In response to a prescription, pharmacists may combine, mix or alter ingredients to create unique medications in accordance with traditional compounding. A compounded drug may be necessary, for example, to treat a patient with a documented allergy to a drug ingredient, or to provide a liquid dosage form for a child who is unable to swallow tablets. A primary tenet of traditional compounding is that an FDA-approved product should be used wherever possible to meet a patient's individual medical needs, because, despite best compounding practices ${ }^{[4]}$ extemporaneous formulations generally lack studies to document stability, bioavailability, pharmacokinetics, pharmacodynamics, efficacy and safety. ${ }^{[5,6]}$ This tenet restricts the use of compounded drugs to where they are medically necessary and protects the public from intentional circumvention of the FDA approval and regulatory process that consumers rely on for safe and effective therapies (table I).

State Boards of Pharmacy oversee pharmacy practices, including drug compounding. When the FDA learns of compounding practices that raise public health concerns, the agency may refer the matter to State Boards of Pharmacy for investigation. ${ }^{[7]}$ Using a risk-based approach, ${ }^{[8]}$ the FDA may take enforcement action against pharmacies for circumstances described in FDA Guidance that are not consistent with traditional compounding, including but not limited to the following: ${ }^{[9]}$

1. Compounding drugs prior to receipt of a valid prescription.

2. Compounding drugs removed from the market for safety reasons.

3. Compounding drugs that are essentially copies of commercially available products.

Table I. Key differences between US FDA-approved and compounded drugs

\begin{tabular}{lll}
\hline & $\begin{array}{l}\text { FDA-approved } \\
\text { drug }\end{array}$ & $\begin{array}{l}\text { Compounded } \\
\text { drug }\end{array}$ \\
\hline $\begin{array}{l}\text { Made 'extemporaneously' } \\
\text { after receipt of prescription }\end{array}$ & No & Yes \\
$\begin{array}{l}\text { Reviewed by FDA for } \\
\text { quality, safety and efficacy } \\
\text { prior to marketing/ } \\
\text { prescribing }\end{array}$ & Yes & No \\
$\begin{array}{l}\text { Manufactured under } \\
\text { federal GMP regulations }\end{array}$ & Yes & No \\
$\begin{array}{l}\text { Labelling for safe } \\
\text { prescribing and use } \\
\text { required and regulated }\end{array}$ & Yes & No \\
$\begin{array}{l}\text { Sterile products adhere to } \\
\text { federal GMP sterility } \\
\text { requirements }\end{array}$ & Yes & No \\
Benefit-risk assessment & $\begin{array}{l}\text { Conducted by } \\
\text { FDA at }\end{array}$ & $\begin{array}{l}\text { Conducted by } \\
\text { prescriber at } \\
\text { patient level }\end{array}$ \\
\hline $\begin{array}{l}\text { GMP = Good Manufacturing Practice. } \\
\text { population level }\end{array}$ &
\end{tabular}


Compounded drugs may be made starting with FDA-approved brand or generic drugs, for example, a tablet or capsule may be converted to a liquid form for administration to a child. Benefits of compounding from approved dosage forms include basic confirmation of the identity of the active ingredient and its initial dose. Potential disadvantages include formulation complications from inactive ingredients that may not be suitable for the compounded formulation.

Compounded drugs may also be made with active pharmaceutical ingredients (API) and other inactive components. Benefits of compounding from APIs include the avoidance of binders, and the possibility of accessing drug substances that are not available in suitable commercial forms for the intended use of the compounded product. For example, an oral tablet may contain inactive ingredients that should not be administered by the intravenous route. If such a drug is necessary, it may be preferable to start with an appropriate API, if available. Disadvantages of compounding with APIs include, first and foremost, uncertainty regarding the substance's identity, purity and potency. In addition, due to the complex nature of our global supply chain, an API's origin and disposition throughout the supply chain, including shipping, storage conditions and repackaging, may be difficult for pharmacies and physicians to verify. ${ }^{[10]}$

By necessity, compounded drugs are made under standards that are less stringent than those applied to FDA-approved products. It would be impossible, for example, to apply for FDA approval for drugs compounded on an individual, extemporaneous basis. Further, traditional pharmacies would find it difficult to comply with the complexities of federal GMP requirements under the FFDCA. However, some facilities operating under less rigorous pharmacy standards actually manufacture large quantities of standardized dosage forms without adherence to federal manufacturing standards. Such business practices, deemed by former FDA Commissioner David Kessler, MD, as "manufacturing under the guise of pharmacy compounding," undermine the FFDCA and place populations at risk for substandard drug exposures. ${ }^{[11]}$ Because of the inherent differences between federal manufacturing and approval standards and professional (pharmacy) standards with respect to purpose, scope and enforceability, physicians should be cautious in their judgements regarding what circumstances would justify setting aside a federal standard for a professional one.

\section{1 Risks Associated with Compounded Medications}

Pharmacy-compounded drugs have been associated with quality defects, infectious disease outbreaks and other adverse events which, in some cases, have involved patient deaths. ${ }^{[7,12-17]}$ Because federal surveillance requirements do not exist for compounded drugs, the extent of quality and safety problems is unknown. ${ }^{[18]}$

\subsubsection{Substandard Products}

While surveillance is limited, quality defects have been reported in conjunction with product recalls, as outcomes of formal, limited investigations by the FDA and Missouri State Board of Pharmacy, and as independent studies. ${ }^{[17,19-24]}$

In 2004, roughly 1.4 million doses of compounded respiratory solution contaminated with Burkholderia cepacia were distributed to patients nationally. The Missouri State Board of Pharmacy found the pharmacy did not adequately recall potentially affected product and failed to advise patients and prescribers of the contamination risk. The Board issued a temporary restraining order, noting in their petition that the pharmacy "engaged in practices that pose a threat of immediate and irreparable injury, loss or damage to patients and presents a probability of serious danger to the health, safety or welfare of the residents of the state."'[25]

In 2006, the FDA conducted a limited survey of compounded drugs. Of 36 samples tested by the FDA, 12 failed at least one quality test, for a failure rate of $33 \%$. Further, oral hormone dosage forms containing multiple active ingredients showed poor content uniformity, with random variation in all three active ingredients from capsule to capsule. ${ }^{[19]}$

The Missouri State Board of Pharmacy initiated routine sampling and testing of compounded drugs 
after pharmacist Robert Courtney was found to have supplied thousands of cancer patients with substandard chemotherapy that provided only a fraction of prescribed doses. ${ }^{[2]}$ For the years 2006-2009, the Board of Pharmacy testing revealed that failure rates averaged roughly $20 \%$ (range 11.6-25.2), with individual findings ranging from $0 \%$ to $450 \%$ of labelled potency. ${ }^{[23]}$ While the Courtney case involved drug reconstitution and admixing of FDA-approved products, it is critical to this discussion because it illustrates an important limitation of clinical medicine: the dilution scheme went on for years and affected thousands of patients, yet medical observation alone failed to detect lack of effect, including both therapeutic response and expected chemotherapy-related toxicity. In the absence of federal oversight, clinical observation or experience alone may be a poor surrogate for ensuring the quality, safety and effectiveness of compounded drugs.

In a 2004 published analysis sponsored by STD Pharmaceuticals, ${ }^{[27]}$ all samples purchased from three compounding pharmacies failed content testing for a $3 \%$ sodium tetradecyl sulfate solution for injection (range 2.59-3.39). Significant concentrations of the contaminant carbitol were found to be present in samples from all three sources (0.334.18), suggesting possible use of a non-pharmaceutical grade chemical. In response to the assay results, dermatologist Mitchel Goldman concluded that "Physicians need to be aware that the stated concentration may not be correct and that along with sodium tetradecyl sulfate, potentially harmful contaminants may be present in the solution."

Mahaguna et al. ${ }^{[28]}$ reported an analysis of compounded progesterone suppositories from ten randomly selected pharmacies. Nine of the ten pharmacies provided suppositories that fell outside potency limits set for approved products and one pharmacy provided suppositories testing positive for Comamonas acidovorans bacteria.

In a similar analysis sponsored by Ther-Rx Corporation, eight of nine samples of hydroxyprogesterone caproate API accessible to pharmacies for compounding did not meet impurity standards applicable for manufacturing the approved product and 16 of 30 samples of hydroxyprogesterone injection samples purchased from compounding pharmacies exceeded impurity limits for the approved product. One additional sample of API labelled as hydroxyprogesterone caproate did not contain any active ingredient and was subsequently found to contain only glucose..$^{[17]}$

\section{1.2 Morbidity and Mortality Associated with Compounded Drugs}

Because pharmacies are not required to conduct surveillance or report adverse events associated with drugs they make, the extent of compounded drug-associated morbidity and mortality cannot be assessed. Sentinel events involving compounded drugs have become known through sporadic reporting by the FDA and the Centers for Disease Control and Prevention (CDC), through case reports published in the literature, and through media reporting. These events are considered the 'tip of the iceberg' by public health experts, because there is little if any transparency as to the extent of exposure to non-FDA-approved, pharmacy compounded drugs and the rate of occurrence of adverse events. $^{[12]}$

Examples of preventable adverse events include but are not limited to the following:

- An outbreak of Pseudomonas fluorescens bloodstream infections associated with compounded catheter flush solutions occurred in four states during 2004-5. The CDC noted that sterility testing of finished products, mandated for FDA-approved products, was reportedly not performed in this case and concluded "Companies that manufacture products intended for injection should follow FDA regulations for ensuring the sterility of these products."[14]

- Whelan et al. ${ }^{[15]}$ reported a probable treatment failure in a poorly controlled asthma patient with severe disease. An analysis found that the patient's inhalation therapy contained an average of $36.8 \%$ of active ingredient for the five vials assayed by high-performance liquid chromatography (HPLC). Authors note that these findings highlight major concerns with using compounded products that are not FDA approved.

- A cluster of streptococcal endophthalmitis infections was reported to the FDA by the Florida Department of Health following intravitreal injection of repackaged bevacizumab (Avastin ${ }^{\circledR}$ ). 
At least 12 patients developed eye infections, with some losing all remaining vision. ${ }^{[16]}$

\subsection{Controversial Roles of Compounding}

While there is a place for traditional pharmacy compounding to fulfil medical needs of individuals that cannot be met with commercially available products, these more controversial aspects threaten to circumvent important public health regulations at the population level. Some controversial uses of pharmacy compounding include the introduction of drug moieties that have been denied or removed from the US market, the mass marketing of specific, non-FDA-approved formulations, and the compounding of drugs for economic reasons.

An interesting example involves the drug 4aminopyridine. Although physicians had been prescribing unapproved versions of the drug for up to 20 years, it was not until the drug was studied systematically that rare seizures were discovered as a potential side effect. In this case, the medical profession pushed for an approved version to be marketed, rationalizing that if a seizure occurred in the context of a patient taking an FDA-approved alternative, "at least you know it wasn't because of a local compounding pharmacy error.",[29]

Another significant example has been the rapid growth of the so-called 'bioidentical postmenopausal hormone therapy' market. Following the abrupt termination of the estrogen-progestogen arm of the National Institutes of Health (NIH) Women's Health Initiative Study in July 2002, an alternative market developed promoted by compounding pharmacies and health providers, often with cross-interests. Not subject to the reporting requirements imposed on the pharmaceutical industry, the bioidentical compounding industry has made major claims of absence of risk and maintenance of benefits of hormone therapy, despite the fact that the basic molecules being compounded are, in most instances, the same as those of FDAapproved products. ${ }^{[30]}$ The FDA has found discrepancies and has issued Warning Letters to many compounders, but this alternate industry continues to flourish with major marketing efforts. ${ }^{[31]}$

An example of pharmacy compounding purely for cost-saving purposes involves the recently approved drug, Makena ${ }^{\circledR}(17 \alpha$-hydroxyprogesterone caproate injection). Citing a "unique circumstance," the FDA announced the agency would continue to exercise enforcement discretion and not enforce the FFDCA for compounded versions of the newly approved drug if pharmacies produced the alternatives in accordance with "traditional compounding." [32] The announcement created considerable confusion in the prescribing and reimbursement communities, to the extent that some stakeholders interpreted the FDA enforcement discretion language to mean that compounded versions of $17 \alpha$-hydroxyprogesterone caproate had been approved by the FDA for safety and efficacy. On 29 June 2012, the FDA clarified its regulatory language for prescribers, payers and patients, stating that "when an FDA-approved drug is commercially available, the FDA recommends that practitioners prescribe the FDA-approved drug rather than a compounded drug unless the prescribing practitioner has determined that a compounded product is necessary for the particular patient and would provide a significant (medical) difference for the patient as compared to the FDA-approved commercially available drug product."[8] This statement holds at its very core the fundamental public health values of the FFDCA. FDA-approved products produced under federal GMPs represent an essential standard of pharmaceutical care relied on by US citizens, and deviations from this standard of care should be made only under rare circumstances of medical necessity.

\subsection{Medico-Legal Risks for Physicians}

Few prescribing physicians escape concerns during their day-to-day practice of the 'lawyer looking over their shoulder'. The prescribing of compounded drugs involves the triad of patient, physician prescriber and compounding pharmacy. When prescribing an FDA-approved drug according to labelled indications, in the event of an adverse outcome the physician is protected by the FDA approval process and background support of a major pharmaceutical company, thus unlikely to face personal liability. Unlike FDA-approved products, there is no requirement by compounders to provide a patient package insert listing risks and 
benefits, and the marketing invariably has minimized possibility of risks. Consequently, prescribers of compounded products may be personally exposed should there be an adverse event as a result of administering a product that neither the prescriber nor the compounder can prove to have been pure and free of active contaminants, of correct dose, sterile, etc. ${ }^{[33]}$ Indeed, the FDA has attempted to avoid such risks by its policy against compounding products when an FDA-approved drug exists. Physicians should also be aware that the liability based on inappropriate use of a non-FDA-approved drug can be significant, and possible negative consequences can include the invalidation of their malpractice insurance, personal liability and possible criminal prosecution. This is a situation beyond buyer beware that really is 'prescriber beware'.

Prescribing physicians can lessen malpractice exposure. The simple and direct approach would be to only prescribe FDA-approved products, with the sole exception for those patients who require an alternative form that is not available commercially. ${ }^{[34]}$ If prescribers are motivated to prescribe compounded products, and reduced cost is not legally viable as a sole reason, then that prescriber needs to take some active steps to ensure the patient is receiving exactly what was prescribed. These include ascertaining that an FDA-approved equivalent is not available, acquiring information from the compounding pharmacist as to whether their facility is FDA registered, where the raw product was obtained and whether it is pharmaceutical grade for humans, how the batch is stored, whether it has been tested for purity, how and when the product was compounded including sterility, and whether the equipment is free of contaminants of other drugs. It is strongly recommended that documentation about responses to these queries be included in the patient record, confirming that the prescriber has taken every step available to them to ensure that the patient is receiving the medication prescribed.

\section{Important Considerations for Prescribers}

Compounding practices have emerged throughout the US and other countries as novel pharmacy business models that offer expanded compounding services with direct marketing of unique formulations to patients and prescribers. Because the idea of using a compounded product in today's marketplace may not arise solely from a physician's identification of a medication problem that requires an alternative to an FDA-approved product, physicians should have a basic understanding of the benefits and risks of compounded drugs to support therapeutic decision making and to help educate patients about their treatment options. In this regard, prescribers are reminded of the following:

- That compounded drugs lack an FDA finding of safety, efficacy and manufacturing quality.

- That compounded drugs are not interchangeable with FDA-approved brand or generic medications.

- That, if an FDA-approved drug is available, the FDA-approved product should be prescribed and used.

- That liability concerns may arise due to prescribers' role as a learned intermediary if patient harm arises in association with compounded drugs.

\section{Acknowledgements}

Both authors are current or previous consultants to TherRx Corporation. Sarah Sellers received compensation from Ther-Rx for drafting the manuscript.

\section{References}

1. US Department of Health and Human Services. Food and Drug Administration. Center for Drug Evaluation and Research (CDER). Center for Biologics Evaluation and Research (CBER). Guidance for Industry: providing clinical evidence of effectiveness for human drug and biological products. Rockville (MD): CDER, 1998 May [online]. Available from URL: http://www.fda.gov/downloads/Drugs/ GuidanceComplianceRegulatoryInformation/Guidances/ UCM078749.pdf [Accessed 2012 Sep 27]

2. US Department of Health and Human Services. Food and Drug Administration. Center for Drug Evaluation and Research (CDER). Center for Biologics Evaluation and Research (CBER). Office of Regulatory Affairs (ORA). Guidance for industry: CGMP for phase 1 investigational Drugs. Rockville (MD): US FDA, 2008 Jul [online]. Available from URL: http://www.fda.gov/downloads/Drugs/ GuidanceComplianceRegulatoryInformation/Guidances/ UCM070273.pdf [Accessed 2012 Sep 27]

3. US Department of Health and Human Services. Food and Drug Administration. Center for Drug Evaluation and Research (CDER). Center for Biologics Evaluation and 
Research (CBER). Center for Veterinary Medicine (CVM). Office of Regulatory Affairs (ORA). Guidance for Industry: quality systems approach to pharmaceutical CGMP regulations. Rockville (MD): US FDA, 2006 Sep [online]. Available from URL: http://www.fda.gov/downloads/Drugs/ GuidanceComplianceRegulatoryInformation/Guidances/ UCM070337.pdf [Accessed 2012 Sep 27]

4. US Department of Health and Human Services. US Food and Drug Administration. The special risks of pharmacy compounding [online]. Available from URL: http://www. fda.gov/ForConsumers/ConsumerUpdates/ucm107836.htm [Accessed 2012 Sep 27]

5. Nahata MC, Allen Jr LV. Extemporaneous drug formulations. Clin Ther 2008; 30 (11): 2112-9

6. Glass BD, Haywood A. Stability considerations in liquid dosage forms extemporaneously prepared from commercially available products. J Pharm Pharm Sci 2006; 9 (3): 398-426

7. Galston SK. Federal and state role in pharmacy compounding and reconstitution: exploring the right mix to protect patients. Hearing on Oversight Before the Senate Committee on Health, Education, Labor, and Pensions, 108th Cong. 2003 Oct 23 [online]. Available from URL: http://www.fda.gov/NewsEvents/Testimony/ucm115010.htm [Accessed 2012 Sep 27]

8. US Department of Health and Human Services. US Food and Drug Administration. Questions and answers on updated FDA statement on compounded versions of hydroxyprogesterone caproate (the active ingredient in Makena). 2012 Jun 29 [online]. Available from URL: http://www.fda. gov/newsevents/newsroom/pressannouncements/ucm310215. htm [Accessed 2012 Sep 27]

9. US Food and Drug Administration. Importation of active pharmaceutical ingredients (APIs) requirements CPG 460.200 pharmacy compounding compliance policy guides manual (Tab M). 2002 May [online]. Available from URL: http:// www.fda.gov/downloads/AboutFDA/CentersOffices/CDER/ UCM118050.pdf [Accessed 2012 Sep 27]

10. Gozen EL. Current topics in pharmacy compounding. 2011 May 24 [online]. Available from URL: http://www.nabp. net/meetings/assets/FDA\%20Update.pdf [Accessed 2012 Sep 27]

11. United States Supreme Court: Western States Medical Center et al. Petition for a writ of certiorari. 2001 [online]. Available from URL: http://www.justice.gov/osg/briefs/ 2001/2pet/7pet/2001-0344.pet.aa.pdf [Accessed 2012 Sep 27]

12. Sellers SL. Federal and State Role in Pharmacy Compounding and Reconstitution: Exploring the Right Mix to Protect Patients: Hearing on Oversight Before the Senate Committee on Health, Education, Labor, and Pensions, 108th Cong. 2003 Oct 23 [online]. Available from URL: http://www.pharmwatch.org/comp/sellers.shtml [Accessed 2012 Sep 27]

13. Boodoo JM. Compounding problems and compounding confusion: federal regulation of compounded drug products and the FDAMA circuit split. Am J Law Med 2010; 36 (1): 220-47

14. Pseudomonas bloodstream infections associated with a heparin/saline flush: Missouri, New York, Texas, and Michigan, 2004-2005. MMWR Morb Mortal Wkly Rep 2005; 54 (11): 269-72
15. Whelan GJ, Spahn JD, Brown EE, et al. Subpotentcy of a compounded budesonide for nebulization product in a patient with poorly controlled asthma. J Allergy Clin Immunol 2006; 117: S12

16. US Department of Health and Human Services. US FDA. FDA alerts health care professionals of infection risk from repackaged avastin intravitreal injections. 2011 Aug 30 [online]. Available from URL: http://www.fda.gov/Drugs/ DrugSafety/ucm270296.htm [Accessed 2012 Sep 27]

17. Chollet JL, Jozwiakowski MJ. Quality investigation of hydroxyprogesterone caproate active pharmaceutical ingredient and injection. Drug Dev Ind Pharm 2012; 38 (5): $540-9$

18. Heinrich J. United States General Accounting office. Testimony before the Committee on Health, Education, Labor, and Pensions, U.S. Senate. Prescription drugs: state and federal oversight of drug compounding by pharmacies. 2003 Oct 23 [online]. Available from URL: http://gao.gov/ assets/120/110456.pdf [Accessed 2012 Sep 27]

19. US Department of Health and Human Services. US FDA. 2006 limited FDA survey of compounded drug products. 2010 Mar 22 [online]. Available from URL: http://www.fda. gov/Drugs/GuidanceComplianceRegulatoryInformation/ PharmacyCompounding/ucm204237.htm [Accessed 2012 Sep 27]

20. Crill CM, Hak EB, Robinson LA, et al. Evaluation of microbial contamination associated with different preparation methods for neonatal intravenous fat emulsion infusion. Am J Health Syst Pharm 2010; 67 (11): 914-8

21. Green DM, Jones AC, Brain KR. Content variability of active drug substance in compounded oral 3,4-diaminopyridine products. J Clin Pharm Ther 2012; 37 (1): 53-7

22. Ybarra JV, Rose WE, Curtis CS, et al. Sterility of pediatric lipid emulsions repackaged by an automated compounding device. JPEN J Parenter Enteral Nutr 2011; 35 (3): 391-4

23. Missouri Division of Professional Registration. Board of Pharmacy. Pharmacy compounding report FY 2006-2009 [online]. Available from URL: http://pr.mo.gov/pharma cists-compounding.asp [Accessed 2012 Sep 27]

24. Kato Z, Nakamura M, Yamagishi Y, et al. Pediatric thioridazine poisoning as a result of a pharmacy compounding error. Pediatric reports 2009 Jun 8; 1 (1): e9

25. Missouri Department of Economic Development. Missouri Board of Pharmacy takes action against Kansas City company [media release]. 2003 Mar 10 [online]. Available from URL: http://pr.mo.gov/boards/pharmacy/press/ 2003-10-03.pdf [Accessed 2012 Sep 27]

26. Stagg-Elliott V. Drug diluting in Kansas City: a pharmacist's crime shakes a community. amednews.com 2002 May 20 [online]. Available from URL: http://www.amaassn.org/amednews $/ 2002 / 05 / 20 /$ hll10520.htm [Accessed 2012 Sep 27]

27. Goldman MP. Sodium tetradecyl sulfate for sclerotherapy treatment of veins: is compounding pharmacy solution safe? Dermatol Surg 2004; 30 (12 Pt 1): 1454-6

28. Mahaguna V, McDermott JM, Zhang F, et al. Investigation of product quality between extemporaneously compounded progesterone vaginal suppositories and an approved progesterone vaginal gel. Drug Dev Ind Pharm 2004; 30 (10): 1069-78 
29. Ha K, Krutoholow E. Acorda Therapeutics' fampridine-SR likely to receive FDA approval with REMS/black box label.

Financial Times 2009 Oct 2 [online]. Available from URL: http://www.ft.com/intl/cms/s/2/b7b50454-af64-11de-ba1c00144feabdc0.html\#axzz215F9iIhd [Accessed 2012 Sep 27]

30. US Department of Health and Human Services. US FDA. Bio-identicals: sorting myths from facts. 2008 Apr 8 [online]. Available from URL: http://www.fda.gov/down loads/ForConsumers/ConsumerUpdates/ucm049312.pdf [Accessed 2012 Sep 27]

31. Baker DA, Gass MLS, Utian WH. The truth about bioidentical hormone therapy. The American College of Obstetricians and Gynecologists, Continuing Medical Education $2012 \mathrm{Feb} 1 ; 37$ (8) [online]. Available from URL: http://www.acogupdate.com/?gp_page = p_onecourse \&gp_ skey $=311$ [Accessed 2012 Feb 27]
32. US Department of Health and Human Services. US FDA. FDA statement on Makena [media release]. 2011 Mar 30 [online]. Available from URL: http://www.fda.gov/news Events/Newsroom/PressAnnouncements/ucm249025.htm [Accessed 2012 Sep 27]

33. Mckenna KJ. Compounded sclerosing agents: risks and consequences. Vein Magazine 2008; 1 (2) [online]. Available from URL: http://www.veindirectory.org/magazine/article/ from URL: http://WwW.veindirectory.org/magazine/article/
compounded_sclerosing_agents_risks_and_consequences [Accessed 2012 Sep 27]

34. Krochmal L. Considerations before choosing (extemporaneously) compounded products. Dermatol Ther 2009; 22 (3): $225-8$

Correspondence: Dr Sarah Sellers, q-Vigilance LLC, 106 Carriage Road, North Barrington, IL 60010, USA.

E-mail: sarahsellers@mac.com 